\title{
A mulher em situação de abortamento: um enfoque existencial
}

\author{
WOMEN IN FACE OF ABORTION: AN EXPERIENCE-BASED APPROACH
}

LA MUJER EM SITUACIÓN DE ABORTO: UN ENFOQUE EXISTENCIAL

\author{
Magali Roseira Boemer ${ }^{1}$, Mariana Gondim Mariutti ${ }^{2}$
}

\begin{abstract}
RESUMO
O trabalho se propõe a desvelar facetas do significado do aborto para a mulher que o vivencia. Para tanto, as autoras recorrem a Metodologia de Investigação Fenomenológica-quepossibilita uma análise compreensiva dos depoimentos das mulheres que estão vivenciando essa situação. Foram coletados depoimentos de doze mulheres hospitalizadas, em situação de abortamento, mediante a questão norteadora: "O que está significando para você essa experiência? Vocêpode descrever para mim?" As convergências de suas falas foram analisadas e possibilitaram a construção de algumas categorias temáticas que sinalizam para a essência desse vivenciar e constituem-se em subsídios para nortear o planejamento de assistência à mulher de forma que a sua situacionalidade seja contemplada. Os resultados possibilitaram o desvelamento de facetas importantes, tais como tristeza, perda, dor fisiológica e existencial, solidão, uma hospitalização desconfortante, a culpa ou medo de ser culpada, a preocupação com o corpo e a intencionalidade de suas consciências começando a voltar-se para a importância dos métodos contraceptivos. Resulta também o desejo de rever seus projetos de vida.
\end{abstract}

\section{PALAVRAS-CHAVE}

Aborto. Saúde da mulher. Bioética. Enfermagem Obstétrica.

\begin{abstract}
This work aims at revealing the meaning of abortion in the view of women who have experienced it. For this purpose, the author used the Methodology of

Phenomenological

Investigation, which enabled a comprehensive analysis of the accounts collected. Data were gathered by interviewing twelve hospitalized women. The following questions were used: "What's the meaning of this experience to you? Can you describe it to me? The convergence of their accounts was analyzed and this enabled the creation of thematic categories. Such categories point out the essence of these women's experience and may provide guidelines for the development of assistance policies that would meet their specific needs. The results enlighten important aspects associated with sadness, loss, physiological and existential pain, loneliness, hospitalization discomfort, guilt or fear of being considered guilty, concern with their bodies and the intentionality of their consciences beginning to give importance to contraceptive methods. Their desire to review their own life projects also emerges.
\end{abstract}

\section{KEYWORDS}

Abortion. Women's health. Bioethics. Obstetrical nursing.

\section{RESUMEN}

El trabajo se propone descubrir facetas del significado del aborto para la mujer que lo vivencia. Por tanto, la autora recurre a la Metodología de Investigación del Fenómenoque posibilita un análisis comprensivo de los relatos de las mujeres que están viviendo esa situación. Fueron recogidos testimonios de doce mujeres hospitalizadas en situación de aborto, por medio de la cuestión orientadora: ¿Qué significa para Ud. Esta experiencia? ¿Puede Ud., describirla para mi? Las convergencias de sus charlas son analizadas y posibilitan la construcción de algunas categorías temáticas que señalan la esencia de esa vivencia y pueden constituirse en subsidios para orientar el plan de asistencia a la mujer de forma que su situación sea contemplada. Los resultados posibilitan el conocimiento de facetas importantes, tales como tristeza, pérdida, dolor fisiológico y existencial, soledad, una hospitalización no confortable, la culpa o miedo de ser culpada, preocupación con el cuerpo y la intención de su conciencia comenzando a ver la importancia de los métodos contraceptivos. Surge también el deseo de rever sus proyectos de vida.

\section{PALABRAS-CLAVE}

Aborto. Salud de la mujer. Bioética. Enfermería obstetrica.
1 Professora LivreDocente Aposentada da Escola de Enfermagem de Ribeirão Preto-USP. Orientadora deste estudo. boemer@glete.eerp.usp.br 2 Acadêmica do $4^{\circ}$ ano do Curso de Graduação em Enfermagem da Faculdade de Ciências MédicasUnicamp. tatimorelati@hotmail.com

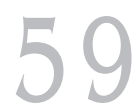

Rev Esc Enferm USP 2003; 37(2): 59-71. 


\section{A GÊNESE DO MEU INTERROGAR}

Durante o programa de Iniciação Científica que percorri no curso de graduação em enfermagem, pude aproximar-me do tema da Morte e perceber a sua importância para o profissional da área de saúde de forma que possa melhor lidar com os momentos em que o morrer está presente na assistência ${ }^{(1-9)}$.

Nessa trajetória, meu interesse e inquietação voltaram-se para as questões que envolvem a mulher e, mais especificamente, as situações de abortamento. Um estudo sobre morte perinatal ${ }^{(10)}$, remeteu-me à questão do aborto, na medida que ele pode impossibilitar o existir do homem e, nesse sentido, direcioneime para esse tema, pois esta impossibilidade de vida se apresentou a mim como objeto de investigação. O aborto é a interrupção da gravidez ou expulsão do produto da concepção antes que o feto seja viável, isto é, antes da $22^{\mathrm{a}}$ semana ou, se idade gestacional for desconhecida, com o produto pesando menos de 500 gramas ou medindo menos de 16 centímetros e segundo o mesmo autor, a situação de abortamento refere-se quando esta interrupção está ocorrendo e as manifestações clínicas estão acontecendo ${ }^{(14)}$.

O aborto é referido como sendo envolto em tabus, preconceitos, discriminações, o que o caracteriza como uma questão polêmica desde a antigüidade(11). Um outro estudo ${ }^{(12)}$ remete-se a dados desde o momento em que as mulheres ficam grávidas e afirmam o desejo de aborto, até realizá-lo. As reflexões deste estudo são pautadas por uma questão de ética e corporalidade, propondo uma visão para além do corpo.

Para os defesores da descriminalização do aborto, a melhor forma é trazê-lo para a legalidade. Após quatorze anos de derrotas em quatro conferências nacionais, a descriminalização foi aprovada pelo plenário da $11^{\circ}$ Conferência Nacional de Saúde. Isto não quer dizer que o aborto tenha deixado de ser crime. Pelo Código Penal Brasileiro, a interrupção da gravidez só é permitida em caso de estupro ou risco de vida para a mãe. Para que o aborto seja tratado como um problema de saúde e não como crime será preciso que os parlamentares aprovem um dos projetos que tramitam no Congresso ${ }^{(13)}$.

Cresce o consenso de que a legislação sobre o assunto está ultrapassada, pois cal- cula-se que ocorram 1,4 milhões de abortos clandestinos por ano no Brasil, sendo os procedimentos mal feitos a principal causa de mortalidade materna no país ${ }^{(14)}$.

Quanto ao futuro da lei, se aprovado, o novo Código Penal vai permitir o aborto em mais uma situação, ou seja, anomalias graves e irreversíveis, quando o feto não tem chance de sobreviver ${ }^{(15)}$. Segundo o autor, a ciência caminhou muito, mas a lei não mudou. Quanto às anomalias fetais, as leis brasileiras representam obstáculos à conduta ética do especialista em Medicina Fetal ${ }^{(16)}$.

No que se refere à questão ética do aborto $^{(17-19)}$ fundamentada em conhecimentos pertinentes à genética e à bioética, a proposta é discutir os seguintes pontos: examinar a realidade biológica do recém-concebido em busca de evidências se o embrião humano é ou não vida humana desde a fecundação e, sendo vida humana, examinar se existem circunstâncias biológicas sob as quais se torna lícito e eticamente aceitável a interrupção da gestação.

A questão bioética do aborto está claramente vinculada ao conceito de início de vida ou, mais precisamente, com a pergunta fundamental: "Quando a vida começa de fato a ter importância moral?"(20)

Essas leituras confirmaram meu interesse neste tema. Para melhor explicitar minha inquietação e delimitar a região da investigação procurei também habitar o mundo do hospital onde são internadas mulheres em situação de abortamento, buscando apropriar-me desse mundo. Com a devida aprovação dos responsáveis, pude conviver com mulheres em diferentes situações de internação, atendidas em situações de urgências ligadas à ginecologia e obstetrícia, o que inclui o aborto, no Setor de Ginecologia e Obstetrícia da Unidade de Emergência do Hospital das Clínicas da Faculdade de Medicina de Ribeirão Preto - USP. Acompanhei todo o percurso dessas mulheres. Expressões de angústia, medo, inquietação, indiferença foram percebidas e se acentuavam à medida em que o desconforto do aborto evoluía.

Toda essa trajetória auxiliou- me mostrando vários aspectos que envolvem uma situação de abortamento, mas o que permanecia oculto para mim era qual seu significado para as mulheres que vivenciavam tal situação. 
Nesse sentido, meu interesse voltou-se para a mulher em situação de abortamento que chegava à instituição. Importava saber o que ela sentia. O significado que atribuía ao vivenciar essa situação, através de suas falas, expressões faciais, gestos e atos, desvelando um lado que permanecia obscuro para mim e que, com sua parceria, propus-me a desvelar. Assim, busquei compreender a situação de abortamento sob a perspectiva de fenômeno, ou seja, enquanto algo que carecia de des-velamento. Para tanto, a metodologia de investigação fenomenológica conduziu esse estudo, buscando pelo significado que as pessoas dão às coisas e às suas vidas, pela via das suas subjetividades. É uma concepção de ciência que se volta para as experiências vividas, do vivido enquanto tal. $\mathrm{Omeu}$ interrogar dirigiu-se à busca da compreensão do significado do abortamento sob a perspectiva das mulheres que o vivenciam, independentemente de sua etiologia biológica. Interessava-me enfocá-lo sob a dimensão existencial. Segundo o referencial fenomenológico, quem pode expressar seus significados são as pessoas que experienciam essa situação, através de suas descrições.

\section{REFERENCIAL TEÓRICO METODOLÓGICO}

Segundo o referencial fenomenológico, fenômeno é tudo que se mostra, se manifesta, se desvela ao sujeito. A fenomenologia vai ao encontro do que se mostra oculto para o pesquisador, não visando a explicação, mas a compreensão. Quando o pesquisador interroga ele está focalizando o fenômeno e não o fato. A fenomenologia tem muita importância na área da pesquisa, produzindo conhecimentos que respondam às indagações do assistir e do cuidar, captando a realidade de algo ${ }^{(21)}$.

$\mathrm{O}$ pesquisador deve procurar colocar-se no lugar do sujeito de forma a não ser apenas um expectador, mas alguém que procura chegar aos significados atribuídos pelo sujeito da mesma forma como este os atribuiu ${ }^{(4)}$. Esta postura empática é fundamental na modalidade fenomenológica, dado que o conhecimento é construído a partir das experiências vividas e aquilo que está sendo investigado não é visto como objeto. É também necessário o reconhecimento do papel da intuição e da subjetividade no processo de selecionar, categorizar e interpretar as mensagens ${ }^{(4)}$. Há três elementos importantes na fenomenologia: a percepção, a consciência que se dirige para o mundo-vida (consciência de alguma coisa) e o sujeito que se vê capaz de experienciar o corpo-vivido através da consciência ${ }^{(22)}$. Para caminhar segundo esse referencial teóricometodológico o pesquisador terá uma trajetória, estará caminhando em direção ao fenômeno, naquilo que se manifesta por si, através do sujeito que experiencia a situação ${ }^{(23)}$.

A forma pela qual os dados são coletados na pesquisa qualitativa é a da comunicação empática entre sujeitos, ou seja, entre o pesquisador e os sujeitos de sua investigação. Nesse sentido, cada sujeito é parceiro do pesquisador no processo de descoberta. As descrições referem-se às experiências vividas, enfatizam o geral e apontam as diferenças nos significados das estruturas gerais, apontando para a estrutura do fenômeno, para sua essência. Por meio do discurso chega-se às condições essenciais do fenômeno. A análise da fala, ou o discurso pronunciado, é que vai permitir que o fenômeno se mostre. As descrições revelam as estruturas do fenômeno, as experiências, sem enfatizar o conteúdo específico, mas enfatizando a estrutura geral e fundamental do fenômeno - a essência ${ }^{(4)}$.

É preciso saber ouvir o discurso do Ser, do sujeito, para que compreenda o que este diz; precisa saber não só ouvir a fala, mas principalmente ouvir o silêncio, porque é nele que o Ser se mostra, se des-vela ${ }^{(24)}$.

\section{O acesso aos sujeitos}

Nessa aproximação com a fenomenologia compreendi que é preciso captar o significado da situação de abortamento aos olhos das mulheres que o vivencia. Contudo, entendo que essa busca não poderia ser obtida por depoimentos das mulheres no momento em que as implicações de natureza fisio-patológicas estão ocorrendo em sua fase mais aguda, o que comprometeria a natureza mesma dos dados e, o mais relevante, comprometeria a postura ética da investigação. Assim, procurei obter a sua fala no período "pós - abortamento". Neste momento, acredito que o vivido por ela se torna presente à reflexão; é ainda um momento que está sendo vivenciado, mas agora como objeto de reflexão.

Os dados foram coletados no Setor de Ginecologia e Obstetrícia de um Hospital Universitário, no período de novembro de
A mulher em situação de abortamento: um enfoque existencial 
Magali Roseira Boemer Mariana Gondim Mariutti
2000 a janeiro de 2001, após obter o aval do Comitê de Ética em Pesquisa da Instituição. Realizei, então, uma entrevista com cada mulher, com a seguinte questão norteadora: $O$ que está significando para você essa experiência? Você pode descrever para mim? Utilizei um gravador, após o seu Consentimento (Termo de Consentimento Livre e Esclarecido). Foram coletados doze depoimentos. Esse número diz respeito ao critério adotado pela Metodologia de Investigação Fenomenológica segundo recomendação de vários autores, não é um número pré-determinado. Quando os depoimentos convergem expressando a "repetitividade" dos discursos, considera-se que parte da essência de um fenômeno foi des-velada. O desvelamento total não é possível pois isso é inerente ao pensamento fenomenológico.

O encontro com cada mulher deu-se na própria enfermaria, quando expus a proposta do estudo e o meu interesse em ouvi-la, explicando que, mesmo com sua autorização, o gravador ficaria próximo a ela e que, no decorrer da entrevista, poderia desligá-lo se o fato de gravar afetasse, de alguma forma, sua disponibilidade para falar. Cabe mencionar que o período de internação foi de um a três dias, dependendo da evolução clínica.

Ao final, perguntava se desejava acrescentar algo mais sobre o seu dizer. Cinco delas pediram esclarecimentos a respeito de métodos anticoncepcionais e duas sobre a "tabela" de controle de fertilidade. Entreguei, então, um manual de métodos de informações sobre contracepção e uma tabela de controle do ciclo menstrual. Após a transcrição, passei à leitura dos depoimentos os quais encontram-se, na íntegra, com os autores à disposição dos leitores.

\section{A forma de análise de dados em fenomenologia}

Nesta abordagem metodológica a análise dos dados não se dá num momento isolado. Assim, o processo de coleta de dados deve ser lento pois o entrevistador precisa ter disponibilidade pessoal de tempo cronológico e de ida ao outro para mergulhar no mundovida dos sujeitos de seu estudo e submergir num processo de descoberta ${ }^{(4)}$.

Outro ponto importante é que para a análise dos dados não existem técnicas ou paradigmas prontos sob os quais o pesquisador possa conduzir e comparar seus resultados, conforme ocorre na pesquisa conduzida segundo a perspectiva das ciências naturais ${ }^{(25)}$. Como a descrição é o recurso de acesso ao des-velamento do fenômeno, ao mundo-vida dos sujeitos, não existe um modelo com o qual se possa contar para proceder à análise dos discursos. Neste sentido, autores de estudos conduzidos sob este referencial ${ }^{(4,20)}$ sugerem apenas um direcionamento para a análise das descrições, que se constitui de quatro momentos.

Inicialmente o pesquisador lê a descrição do início ao fim, familiarizando-se com o texto que descreve a experiência vivida pelo sujeito, procurando colocar-se no lugar deste.

No segundo momento o pesquisador lê novamente cada discurso, mais lentamente, colocando em evidência os significados da descrição, focalizando o fenômeno que está sendo pesquisado.

Obtendo as unidades de significados, o pesquisador expressará o significado contido em cada uma das unidades identificadas. A unidade será mais importante quando mais "revelar" o fenômeno considerado. Quanto à existência de critérios, um deles é o da repetitividade; entretanto, embora importante, não é o único.

O pesquisador sintetiza todas as unidades de significados para chegar à estrutura do fenômeno.

Em todos esses momentos é necessário analisar os dados, questioná-los amplamente a fim de ajudar o pesquisador a manter o foco de atenção no todo ${ }^{(4)}$.

\section{CONSTRUÇÃO DOS RESULTADOS}

Na busca pela compreensão passei à leitura atentiva dos doze depoimentos, buscando apreender nas suas falas o significado deste experienciar. Procurei voltar o meu olhar para a mulher-que-aborta, despojando-me de quaisquer conceitos sobre a temática.

É por meio da fala, do dizer de cada uma sobre a experiência, que o fenômeno se mos$\operatorname{tra}^{(4)}$. Busquei aproximar-me das experiências vividas de cada mulher, de forma a apreender o significado da situação de abortamento tal como por ela atribuído. Assim, destaquei o 
que se mostrou a mim, sob a minha perspectiva, sob o meu olhar, procurando chegar, dentro de meus limites, aos mesmos significados atribuídos e revelados pelas mulheres. Apreendi, por meio de sua descrições, facetas reveladoras da essência do fenômeno do abortamento. Cabe mencionar que as idades das mulheres situavam-se entre 15 a 43 anos. Três delas solteiras, cinco casadas, duas amasiadas e duas desquitadas. Quanto ao nível de instrução, variou de analfabetismo ao $2^{\circ}$ grau incompleto. Quanto à ocupação, três eram estudantes, duas do lar, quatro desempregadas, duas domésticas e uma vendedora de loja. Dentre as doze, três eram primigestas e, para as outras, o número de filhos variou de um a cinco. Duas revelaram já ter passado pela situação de abortamento, sendo que para uma, essa situação está ocorrendo pela quinta vez em sua vida.

Dentre as doze mulheres, nove não haviam usado nenhum tipo de contraceptivo durante as relações sexuais, independente da duração do relacionamento com os parceiros. Nos três casos em que houve o uso de contraceptivos, observei o desconhecimento sobre possibilidade da não eficácia do método, quando usado de modo irregular. Pude, ao final das entrevistas, conversar sobre métodos anticoncepcionais e a importância de planejar a vinda de um filho.

Assim, a análise compreensiva dos depoimentos revelou-me que, aos olhos dessas mulheres, o estar vivenciando a situação de abortamento se mostra:

\section{Como uma experiência permeada por grande dor}

Vejamos alguns discursos que revelam que o abortamento foi experienciado como um momento do qual fazem parte sentimentos como tristeza, perda, solidão e dor. As falas mostram a expressão desse "estar sofrendo":

\footnotetext{
....é ruim viu....é triste... nossa passei uma barra sozinha em casa...com dor...quando eu vi aquele sangue eu chorei, chorei bastante...uma dor que é incompatível...nunca senti uma dor dessa tão forte e nessas horas foi que eu queria um apoio, alguém do meu lado (7) (a)
}

Foi possível perceber as diferentes naturezas da dor. A dor fisiológica e a existencial, isto é, da perda. Essa polaridade da dor é evidenciada nesta fala:

Tive muita dor por dentro e por fora. Em tudo, no coração, dentro...chorei muito (9).

A dor de natureza existencial é percebida com maior intensidade nas mulheres que haviam planejado a gravidez. Ao lado das manifestações verbais desses sentimentos, há de se considerar outras formas de expressão não verbais que se revestem de importância ímpar em situações de sofrimento: o choro silencioso, assim como momentos de silêncio que permeavam as falas.

Como já mencionei, não houve preocupação em identificar as causas do aborto, principalmente no que se refere a ele ser espontâneo ou provocado. Entretanto, embora sendo outra a região da investigação, obviamente que a história clínica, o exame físico e as histórias de vida sinalizavam, em alguns casos, para uma intencionalidade no ato de abortar.

A análise dos discursos permitiu observar que a situação de abortamento gera sentimentos dolorosos para a mulher. Assim, um planejamento da assistência de enfermagem precisa percorrer o caminho de ajudá-las na expressão desses sentimentos. A enfermagem, por estar em contato maior com a mulher, deve estar atenta às essas expressões, facilitando-as e respeitando os momentos de discurso e de silêncio.

Foi sensível o seu alívio ao verbalizar sua dor, suas emoções, sem medo de julgamento ou necessidade de defender-se ou justificarse. Algumas revelam a natureza frágil dos relacionamentos afetivo-sexuais que mantém com os parceiros, as relações conjugais e também o sofrimento com a ausência, incompreensão e descaso do parceiro:

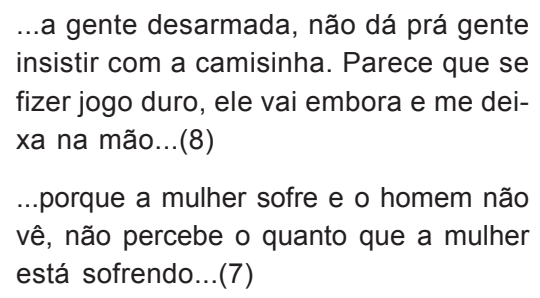

O papel masculino foi esquecido no estudo da prática da ginecologia e obstetrícia, mas é preciso que aos homens sejam ensinados e
A mulher em situação de abortamento: um enfoque existencial
(a)Todos os números entre parênteses alinhados logo após as citações, referem-se aos números dos discursos originais. Portanto, esses números não remetem às referências.

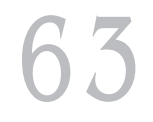

Rev Esc Enferm USP 2003; 37(2): 59-71. 
aprendam o exercício do direito do casal para a tomada de decisões ${ }^{(26)}$.

Um estudo ${ }^{(20)}$ revela que o aborto é tratado como um problema de saúde pública, onde suas diferentes conseqüências recaem sobre a mulher, vítima de uma sociedade que a castiga de forma isolada, como a única responsável pela gravidez, sendo clara a lei brasileira quando diz que o aborto é crime passível de prisão para a mulher e para a pessoa que o comete. Ficando o homem isento das responsabilidades do seu ato sexual, respaldado pelas questões de gênero (papéis diferentes no contexto social). Sendo que o homem, enquanto marido/companheiro, uma vez conhecendo as conseqüências do aborto provocado, pode contribuir para a minimização das seqüelas do organismo da mulher advindas dessa prática, além de diminuir seus conflitos e dividir responsabilidades na tomada de decisão e as famílias e os amigos também ${ }^{(20)}$.

Diferentes situações conferem algumas especificidades diante dessa experiência, tais como: idade, presença ou não do parceiro, condições de moradia, fatores sócioeconômicos, religião, distância do marido que trabalha fora, desejo ou não de ter o filho.

Esse estudo não teve como proposta identificar a etiologia do aborto. Entretanto, alguns discursos sinalizam que, para algumas dessas mulheres, houve uma intenção no ato de abortar e, nesse sentido, vale lembrar que, o que à primeira vista parece ser uma decisão individual envolve uma série de circunstâncias interligadas à qualidade e perspectivas do relacionamento, dos projetos de vida, das pressões familiares, sociais vividas e a vida afetiva $^{(27)}$.

O que se mostra nas falas é que é preciso alcançar esta mulher em outra dimensão além do cuidar biológico, olhando atentivamente para o seu existir enquanto pessoa inserida em um contexto existencial. As ações de enfermagem se revestem de grande importância no cuidado a ela, considerando que a natureza do cuidar envolve uma proximidade física, um maior acesso ao corpo. Diz respeito também a uma questão de gênero, dado que a enfermagem vem sendo exercida predominantemente por mulheres, favorecendo algum compartilhamento.
Como uma experiência que requer uma hospitalização que se mostra desconfortante

As mulheres revelam que percebem esse tempo de hospitalização como muito longo, que demora a passar. O tempo de internação até a curetagem e, posteriormente, até a alta é esperado com muita ansiedade pela maioria das mulheres, apesar do tempo médio de internação ser de dois a três dias dependendo da evolução clínica da mulher. $\mathrm{O}$ desejo de retornar às suas casas emerge em suas falas:

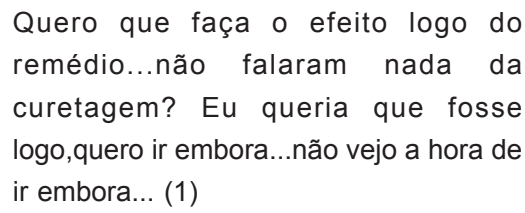

Há nesse desejo de retorno uma certa esperança de "esquecer o ocorrido". Estar hospitalizada lhes remete à causa dessa hospitalização. Tanto para as mulheres que verbalizaram ter planejado a gravidez, assim como para as outras, há essa necessidade de retornar à casa; porém, para as que haviam planejado a gravidez esse desejo se fazia menos ansioso. Talvez esse retorno pudesse ajudá-las a atenuar essa angústia.

Foi relatado o medo de que pessoas significantes descobrissem o ocorrido e, nesse sentido, o tempo de hospitaliação assume grande relevância:

\footnotetext{
Meus pais vão ligar em casa, né...porque eles moram em G, e eu em república...a única pessoa que sabe que eu estou aqui é uma amiga minha da república, se meus pais ligarem lá eu peço para falar que eu fui dormir na casa de uma amiga para estudar (8)
}

Vale lembrar que, algumas mulheres em situação de abortamento por elas induzido buscam por assistência porque apresentam restos ovulares ou embrionários e, com receio da censura familiar e da discriminação social, enfrentam a internação hospitalar sozinhas, sem que os familiares tomem ciência do fato. O abortamento provocado traz consigo um estigma, vinculado à crime, à pecado. Estes preconceitos e tabus acarretam sérios problemas psicossociais, levando muitas mulheres a enfrentarem sozinhas 
a internação a fim de não serem identificadas pela sociedade, nem serem alvos de curiosidade $^{(28)}$.

A solidão, falta de apoio, o medo dos olhares que poderão culpá-las são facetas que permeiam a situação; a solidão é sentida por todas as mulheres independente da causa do aborto. Algumas fixavam seus olhos no nada. O que as incomodava no local era o não parar de pensar, de refletir. Às vezes, o silêncio as incomodava:

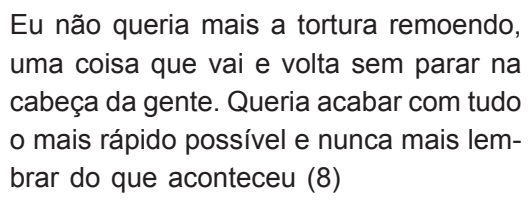

De certa forma, o fato de permanecer hospitalizada por um tempo que é sentido por elas como muito longo as coloca numa situação de ter ao seu redor pessoas que, necessariamente, sabem da situação pela qual estão passando. Ainda que não importe determinar a causa do aborto há um certo sentimento de culpa ou constrangimento, seja nos casos sugestivos de aborto espontâneo ou para aqueles que sinalizam para uma intenção de abortamento. Assim é que durante o convívio com essas mulheres observei que raramente se deslocam da enfermaria para outras áreas do hospital, como se quisessem que suas presenças fossem o menos notadas possível.

O desejo de ter ou não um filho, de ter ou não provocado um aborto, da situação econômica da família e da idade gestacional não interferem no sentido de amenizar ou intensificar a dor dessa perda. Portanto, a expressão desse pesar é extremamente pessoal ${ }^{(14)}$.

\section{Como uma experiência que traz consigo uma culpa ou medo de ser culpada}

O julgamento que pode haver por parte das pessoas exterioriza os parâmetros valorativos da nossa sociedade sobre a questão da maternidade como destino da mulher ${ }^{(28)}$.

O direito sexual da mulher não tem, necessariamente, que estar ligado aos direitos reprodutivos. Segundo o autor, a maternidade, infelizmente, é quase uma obrigação em nossos países, sendo vista como uma consequência lógica: se há atividade sexual, deve haver casamento ou filhos ${ }^{(26)}$. Porém, quem deve decidir sobre ter ou não filhos, e quando os ter, é a mulher. Isso diz respeito a toda filosofia do planejamento familiar ${ }^{(26)}$. Diante disso, julgo ser necessário que os profissionais reflitam ao cuidar dessas mulheres para que esse cuidar não seja norteado por algum julgamento segundo seus valores pessoais. É importante o respeito ao silêncio das mulheres nesse momento. O fato de algumas delas não se manifestarem, explicitamente, através de choros ou expressões de tristeza, não significa que a situação não se apresente como uma situação de dor e, nesse sentido, nos alerta $^{(24)}$ para a significância do silêncio na linguagem humana.

Além dos vários sentimentos já mencionados na primeira categoria temática, as mulheres têm um sentimento de culpa ou medo. Medo de ser culpada, tendo necessidade de se explicar. Suas falas revelam o medo do julgamento moral das pessoas:

Às vezes, a pessoa olha assim, e muitos lá de fora falam, é porque tomou remédio, às vezes a pessoa que está passando por isso não tem nada ver o que as pessoas comentam, sempre vai ter uma crítica, ahhh! como é que espontaneamente vai ter um aborto..., não vou negar esse homem aí estava querendo pagar prá mim tirar, mas eu ia ter esse filho eu daria prá minha mãe toma conta...eu pensei não acho que não tem dinheiro no mundo que vai pagar quando eu chegar lá prá conversar com o Senhor, prestar uma conta...eu não quero essa culpa não...porque sempre vai ter uma dúvida no ar prás pessoas que me conheciam, será que foi espontâneo ou foi provocado? Mas eu fico feliz porque minha consciência ta tranqüila. (7).

As expressões utilizadas para expressar os significados que atribuem ao abortamento são reveladoras de uma situação sofrida e conflituosa: a culpa sentida por si mesma e a culpa de um julgamento por parte dos outros. Muitas mulheres aparentavam ter receio de olhar-me diretamente, abaixavam a cabeça muitas vezes, sentiam necessidade de explicar, de falar que não tinham culpa, talvez, por ser o aborto um tema envolvido em tabus e gerador de tanta polêmica. Entendo que a culpa que sentem não é, necessariamente, por ter tido eventual intenção de aborto. Mesmo para as mulheres com histórias bastante su-
A mulher em situação de abortamento: um enfoque existencia 
Magali Roseira Boemer Mariana Gondim Mariutti gestivas de aborto espontâneo, essa culpa emerge. É uma culpa de outra natureza, por não ter conseguido levar à termo a gestação.

Alguns funcionários da enfermagem, no ato de cuidar dessas mulheres, o fazem de forma diferente dependendo da provável etiologia do aborto. Mulheres com histórias clínicas sugestivas de aborto provocado são vistas como irresponsáveis. Não observei tão claramente isso quando se trata dos médicos; para eles o importante era o biológico. Isso pode ocorrer talvez por se tratar de um Hospital - Escola ou poderia ser uma questão de gênero ou até mesmo uma diferença entre os atos cuidar e de curar.

Há um trabalho que ${ }^{(29)}$ atenta para o significado do cuidado do paciente com AIDS, relatando esse cuidado envolvido por sentimentos de medo, receio e pena do indivíduo no caso do vírus ter sido adquirido por transfusão sanguínea; nos casos de homossexuais, drogados e prostitutas, emergem a censura e o julgamento por parte dos funcionários da enfermagem. E outro $^{(30)}$, um estudo sobre suicídio, também observaram a intolerância e incompreensão que as pessoas têm no ato de cuidar dos indivíduos suicidas. $\mathrm{O}$ autor $^{(6)}$ denuncia a existência de um certo preconceito em torno da pessoa que tenta o suicídio, expresso pelo desprezo, agressividade.

Os médicos estão preparados tecnicamente para lidar com as conseqüências e complicações do aborto, mas não moralmente ${ }^{(31)}$.

Não me deparei com uma situação explícita de aborto provocado, mesmo porque há mecanismos que o mundo do hospital usa para fugir dessa questão e se ater ao que entende ser seu papel: cuidar biologicamente da mulher em situação de aborto. Há dificuldade em aproximar-se academicamente do tema do aborto intencional devido às implicações jurídicas, o que torna difícil e rara a sua caracterização nas situações hospitalares ${ }^{(11)}$. Não sendo possível uma afirmação, trabalha-se com probabilidades de aborto intencional e, assim, com base em um conjunto de fatores (história clínica, exame físico) um provável aborto provocado recebe a denominação de aborto inevitável ou infectado. Esse contexto envolve um conviver dos profissionais de saúde com uma questão polêmica, considerando que não dispõem de diretrizes e suporte para outras formas de ação.
O diálogo é muito importante, pois para se concluir pelo diagnóstico de aborto provocado, além dos dados clínicos e do exame ginecológico, o tocólogo também se vale da informação correta do paciente e, somente com uma boa interação e confiança na relação médico-paciente ${ }^{(32)}$.

O aborto envolto por critérios éticos, morais e religiosos incomoda as mulheres, levando-as ao sentimento de culpa ou medo de ser culpada pelo modo com ela está encarando a situação. Pude apreender esse medo através de sua fala:

Não sei se de repente alguém pode pensar que eu sou uma menina fria por pensar assim, entendeu? Do modo como eu estou encarando toda essa situação, para mim tinha que acontece isso, não era o momento de ter um filho agora(11)

Muitas vezes, o abortamento induzido é apresentado como uma decisão egoísta e fria. Assim, de acordo com esse ponto de vista, a mulher é vista como uma crimino$\mathrm{sa}^{(28)}$. De acordo com o Código Penal Brasileiro, não se pune aborto provocado por médico se não há outro meio para salvar a vida da gestante, se a gravidez resultar de estupro $^{(20)}$.

Os abortos "a pedido" são os abortos realizados por desejo da gestante. Classificados como ilegais, estão sujeitos a uma série de sansões por serem considerados crime. Os motivos que levam a uma mulher a engravidar, sem o desejar, são vários e das mais diversas ordens. Às vezes, nem ao menos é clara essa rejeição. Por um lado, a desinformação; outras vezes, o aborto é conseqüência de falhas do método contraceptivo adotado. Há ainda outros motivos que levam a mulher a não desejar engravidar e, quando isso ocorre, opta por um aborto, ou por entender que o número de filhos que possui já é suficiente, ou pelo fato de que outro filho significaria uma despesa com a qual não poderia arcar. Pode ainda advir da necessidade de trabalhar para tentar melhorar a situação econômica ou por realização pessoal; ou, simplesmente, por não incluir filhos no seu projeto de vida. Por mais livre que a mulher esteja dos padrões morais e religiosos e por mais consciente da sua impossibilidade de levar a termo sua gestação e ainda por mais indesejada que tenha sido a gravidez, abortar é uma decisão que, na 
maioria das vezes, envolve angústia e culpa. Culpa nem se sabe exatamente do quê, mas ela surge mesmo quando existe uma decisão clara de que o aborto foi o passo mais correto que poderia ter sido dado. É uma opção que tem que ser respeitada ${ }^{(14)}$.

Entendo que há outros horizontes de possibilidade para a mulher em sua trajetória de controle da sua fecundidade e que incluem, necessariamente, a educação, o pronto acesso aos Serviços de Saúde, uma preocupação genuína com a saúde integral da mulher. São caminhos que a respeitem como cidadã livre para fazer escolhas, mas que não impliquem, necessariamente, em uma aceitação plena do aborto. Assim, compreender as falas das mulheres se constitui numa possibilidade de acesso ao seu ser, lembrando que o respeito e a interação são importantes para entendê-las em sua situação de abortamento.

\section{Como uma experiência que envolve uma preocupação com o corpo}

Nos seus discursos há uma explicitação veemente da sua preocupação com a integridade do próprio corpo, com o que ele venha a sofrer durante a curetagem e um medo de não poder mais gerar uma criança, conforme expressa o depoimento:

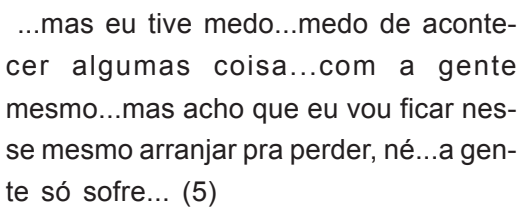

Essa preocupação está relacionada às complicações e conseqüências do aborto já mencionadas. Outra seqüela do aborto, tão importante quanto as descritas, ocorre a nível emocional. Há riscos para o abortamento, inerentes a qualquer procedimento cirúrgico, mesmo quando executado com técnica perfeita e em ambiente $\operatorname{adequado}^{(32)}$.

Nesse meu "conviver-com" as mulheres, observei o suscitar de um sentimento de insegurança, emergindo preocupação de que, na curetagem, "estarão mexendo" num órgão seu muito importante, o útero e, ao lado do medo face a impossibilidade de vir a ter outros filhos, surge a verbalização de adiar essa vinda ou até de pensar em não ter filhos nunca mais: ...agora eu pretendo esperar ó daqui uns cinco anos e olhe lá ainda...eu peguei trauma...pensei até em não ter filhos nunca mais. (9)

Fiquei com medo de acontecer alguma coisa, porque está mexendo no seu útero, né, uma coisa mais séria,...sei lá, de acontecer alguma coisa e eu não poder ter mais filhos... (11)

Pude observar as mais variadas posturas das mulheres frente ao aborto. $\mathrm{O}$ medo que se expressa pelo rosto pálido, mãos úmidas ou trêmulas, voz baixa e insegura que, em conjunto, mostram o seu modo de encarar e lidar com a situação que está vivenciando.

O desvelamento dessa faceta é de importância fundamental para o cotidiano dos profissionais de saúde que atuam nessa área pois, num processo de interação com essas mulheres, eles precisam estar atentos para essas questões. Não só para a questão da preocupação com o corpo, mas também com o medo de ser culpada. Proponho a compreensão dessa situação de abortamento, analisando o contexto sócio-econômico e afetivo em que se encontra essa mulher, sua história de vida, história conjugal. É preciso estar atento para não modificar o ato de cuidar segundo a etiologia do aborto, ou cuidar sob certo julgamento moral em relação a essa mulher. Para as mulheres que já têm um ou mais filhos, o medo da impossibilidade de uma nova gravidez é menor e o modo de encarar a situação de abortamento se modifica. A impossibilidade de uma nova gravidez se apresenta muito ameaçadora para algumas mulheres, pois o seu desejo é ser mãe pelo menos uma vez em sua vida.

Ainda da análise compreensiva desses depoimentos entendo que o fato de revestir o filho de uma identidade parece dar, aos olhos da mulher, uma existência a ele, ainda que sua "morte" tenha ocorrido. Há estudo ${ }^{(10)}$ que também observou essa faceta quando investigou a morte no período perinatal.

\section{Como uma experiência que traz consigo o desejo de rever projetos de vida}

As mulheres fazem projetos no sentido de mudar os rumos de suas vidas, a pensar nelas mesmas e nos outros filhos. Sobretudo, manifestam a intenção de que uma nova
A mulher em situação de

abortamento: um

enfoque existencial 
Magali Roseira Boemer Mariana Gondim Mariutti

gravidez seja planejada e, nesse sentido, interessaram-se em saber sobre métodos contraceptivos e falaram da dificuldade de adesão a eles, principalmente nas situações que requerem envolvimento do parceiro:

Hoje, eu quero dar um futuro melhor pros meus filhos...porque criança não tem culpa do que os pais fazem...hoje eu quero mais ser dedicada, meus estudo.... (7)

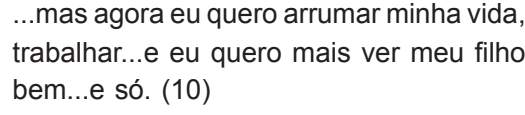

A história de vida dessas mulheres, que inclui algumas características já mencionadas, mostrou-se através de algumas falas relevantes nesse desejo de mudar os rumos de suas vidas. Assim, nesse momento verbalizaram a situação desconfortante de dependência em relação ao marido, principalmente àqueles que as maltratam e têm relações sexuais extra-conjugais. Essa dependência mostrou-se a mim de várias naturezas, tanto econômica como afetiva. Algumas revelaram que se casaram muito novas para libertarem-se da casa dos pais, interrompendo os estudos, tornandose "escravas" do marido:

Eu arrumei ele porque eu não queria cair
na vida, que eu acho que a pior coisa é a
mulher se sentir largada...sabe...jogada,
mesmo...esse meu último filho eu queria
ter com a pessoa que eu amasse, que
fosse pra viver comigo e desse carinho,
afeto a mim e a meus filhos (7)

Larguei tudo para ficar com ele, eu tinha 14 anos... agora eu lavo, passo, faço comida e chega à noite ainda quer... (7)

Esse momento lhes abre possibilidades para pensar em si mesmas, para refletir, num processo de revisão de suas vidas. Verbalizam a vontade de serem independentes. $\mathrm{O}$ aborto parece trazer consigo o desejo de mudanças significativas no seu modo de vida, entre o "antes" e o "depois" da situação. Algumas referem que é algo que pode ser evitado, isto é, se não há desejo de ter filhos no momento, porque não prevenir?

Nunca mais quero passar por isso...agora quero planejar melhor...(7)

Agora vou evitar...(11)

Entretanto, há momentos de resistência ao ato de prevenir nova gravidez, tanto por parte do parceiro, como da própria mulher em todo seu contexto de vida. O tema da sexualidade é tratado com pouca naturalidade e, apesar de eu ter buscado um diálogo, com uma boa interação e confiança na relação sujeitopesquisador, suas falas são permeadas por sentimentos de vergonha.

O desvelamento dessa faceta permite algumas observações pertinentes à atuação da equipe de saúde e, particularmente, dos profissionais de Enfermagem. Percebi a dualidade mente/corpo que se apresenta aos funcionários de forma dicotomizada: de um lado, as tarefas e procedimentos e, de outro, o "apoio psicológico" e a visão do paciente em sua integralidade.

As mulheres expressam suas dificuldades em relação a seguir métodos contraceptivos, a ter diálogos com o parceiro e verbalizam o desejo de transformações nessa esfera. Esse estudo vem mostrar que nesse momento de sua vida a mulher está mais receptiva para ver as possibilidades de mudanças em sua existência. Segundo a perspectiva fenomenológica, a intencionalidade de suas consciências está começando a voltar-se para a importância do uso de métodos contraceptivos.

Assim, é um momento fecundo para orientá-las a prevenir-se; há muitos caminhos para essa orientação. Pode-se trazer essa mulher para os Serviços de Saúde (principalmente os de nível primário), envolvendo também o seu parceiro. É necessária uma melhor articulação dos hospitais de atendimento a complexidades e as Unidades Básicas de Saúde no sentido de, efetivamente, inserí-las em Programas de Saúde da Mulher. Com os avanços da informatização pode ser facilitado o agendamento do horário na UBS no momento das altas dessas mulheres; outro caminho seria esse agendamento ser realizado através do Hospital pois, como já foi mencionado, a intencionalidade de suas consciências está começando a voltar-se para a importância do uso de métodos contraceptivos. Há também a possibilidade da enfermagem em saúde pública atuar realizando visitas domiciliares assim que ocorrer o retorno às suas casas.

Todas essas estratégicas são importantes dado seu potencial transformador nas distintas facetas que envolvem e são envolvi- 
das pelo tema do aborto. O vínculo empático é importante no sentido dessas mulheres sentiram se à vontade para esclarecer dúvidas, falarem de seus medos, das dificuldades de aderir ao anticoncepcional (pílulas), ou de pedir ao parceiro o uso do condom, da incompreensão dos parceiros com objetivo de ouvi-las, identificar problemas, fatores e buscar soluções, ou seja, estar atenta às suas possibilidades de projetar-se para outras dimensões de seu ver a sua vida.

São propostas difíceis de serem colocadas em prática, pois envolvem uma série de fatores que podem ser restritivos para adoção de medidas que possam reduzir o número de abortos, sofrimentos e complicações para a mulher e também o custo para os serviços públicos de saúde. Alerta-se para a importância do direito à educação e às informações, lembrando que se uma pessoa não tem acesso a informações verdadeiras, científicas e oportunas não pode tomar decisões ${ }^{(26)}$.

O aborto tem sido estudado por diversos autores e sob diferentes abordagens como fenômeno social e como problema de saúde; é um fator de alta incidência no que diz respeito à morbidade materna e estão associados à falta de assistência médica, de acesso a informações e a métodos contraceptivos $^{(27)}$.

Não chegaremos à saúde sexual sem uma educação da sexualidade, que até agora esteve muito ligada aos aspectos morais e religiosos, prevalecendo muitos mitos e tabus, em detrimento de uma educação direcionada a evitar riscos desnecessários, como as infecções de transmissão sexual ou a gravidez indesejada que, posteriormente, trarão outras conseqüências ${ }^{(26)}$.

Vale salientar também a importância da atenção às mulheres que desejam engravidar e não conseguem levar sua gestação adiante. Elas precisam de um acompanhamento, uma orientação, uma pessoa disponível para ouví-las, com o empenho em compreendêlas em sua situação. Quando a gravidez foi planejada há um sentimento de frustração com maior intensidade que quando não planejada. Duas mulheres desse estudo haviam planejado a gravidez. Nota-se a frustração nessa fala:
... para mim foi terrível, eu queria muito o filho. Uma mulher sempre quer ser mãe... e a hora que ela tem oportunidade ela quer agarrar com todas as forças (3)

\section{AEXPERIÊNCIADEABORTAMENTO:} GRAUS DECOMPREENSÃO

Em minha proposta de compreensão do significado da situação de abortamento, aos olhos da mulher que o vivencia, percorri uma trajetória metodológica que possibilitou o desvelamento de algumas facetas relevantes dessa situação quanto à assistência a essas mulheres. Trazer à luz perspectivas de compreensão desta experiência pode se constituir em subsídios para nortear o planejamento da assistência a essa mulher que contemple o seu experienciar. Assim, tal planejamento não poderá percorrer o caminho da elaboração de modelos normativos, uma vez que a questão do aborto é essencialmente individual e envolve todo um contexto sócio-econômico, afetivo e religioso.

Neste sentido, a trajetória em busca do aclaramento do fenômeno mostrou que este tema tem sido envolto por tabus, critérios éti$\cos$, morais e religiosos, principalmente pela característica de nossa sociedade de santificar a maternidade. É importante que os profissionais reflitam sobre suas posturas, pois, apesar desse estudo não ter tido a preocupação de identificar a etiologia do aborto, obviamente que a história clínica, o exame físico e as histórias de vida sinalizavam, em alguns casos, para uma intencionalidade no ato de abortar.

Alguns funcionários da enfermagem, no ato de cuidar de mulheres em situação de abortamento, o fazem de forma diferente dependendo da provável etiologia do aborto, isto é, mulheres com histórias sugestivas de aborto provocado. Entretanto, esse cuidado deveria ser de ajuda e orientação proporcionando um atendimento que contemple sua situacionalidade e temporalidade.

As convergências analisadas evidenciam facetas diante das quais a enfermagem poderá nortear sua assistência, tais como a possibilidade da mulher expressar essa grande dor fisiológica e existencial, sentimentos de tristeza, perda, solidão, sua preocupação com o corpo, sentimentos de culpa ou medo de ser culpada e a expressão de seus desejos de re-
A mulher em situação de abortamento: um enfoque existencia 
ver projetos de vida. Esse momento mostrouse fecundo para orientá-las.

Durante a realização desse trabalho, foi possível perceber a necessidade de outros estudos que contemplem questões ligadas ao significado dessa situação aos olhos da equipe de saúde. Julgo também as ações de enfermagem muito importantes no cuidado, considerando que o ato de cuidar envolve uma proximidade física, um maior acesso ao corpo. Há de se considerar ainda que um grande contingente do pessoal de enfermagem é constituído por mulheres, implicando, de certa forma, em um relacionamento entre cuidador e paciente potencialmente empático, onde a cumplicidade, a parceria e a comunhão de questões ligadas ao exercício de ser-mulher podem estar presentes.

É necessária uma busca por novos horizontes, o que inclui a educação e o pronto acesso aos Serviços de Saúde Integral da Mulher. É uma tarefa a ser perseguida e, está nas mãos de todos nós por meio de uma educação sexual mas aberta, sincera, científica, apegada aos direitos e à realidade, sendo uma situação multifatorial, onde não existe somente um responsável, pois há falhas institucionais no setor de saúde quanto à acessibilidade real da educação sexual com respeito e liberdade o que, segundo o autor, inclui a responsabilidade livre de mitos e tabus, mas que falem dos riscos em geral; existem também falhas na dinâmica familiar, pois agora não só os pais trabalham fora, mas as mães também têm que fazê-lo, gerando certo afastamento $^{(26)}$

Este autor assinala também o fator econômico que, inegavelmente, influi no comportamento sexual, principalmente nas camadas mais pobres. Há falhas nos aspectos da formação religiosa, necessitando-se de uma crença que defenda um ponto de vista do que é bom, mais positiva do que negativa.

O abortamento não deve ser justificado e sim compreendido. Atitudes de curiosidade ou de reprovação são inúteis e não ajudam a resolver o grande problema de saúde pública em que se transformou o aborto. As atitudes de reprovação fazem com que os profissionais desmereçam a confiança neles depositada ${ }^{(32)}$.

\section{REFERÊNCIAS}

(1) Ariès P. História da morte no ocidente: da idade média aos nossos dias. Trad. Priscila Vianna de Siqueira, Rio de Janeiro: F Alves Ed; 1977.

(2) Beauvoir S. Uma morte muito suave. Trad. de Álvaro Cabral. Rio de Janeiro: Nova Fronteira; 1984.

(3) Boemer MR. A morte e o morrer. $3^{a}$ ed. Ribeirão Preto: Holos; 1998.

(4) Boemer MR. A condução de estudos segundo a metodologia de investigação fenomenológica. Rev Lat Am Enferm 1994; 2(1):83-94.

(5) Callanan M, Kelley P. Gestos finais. Trad. de Mirna Pinsky. São Paulo: Nobel; 1994.

(6) Cassorla R. Da morte: estudos brasileiros. $2^{\mathrm{a}}$ ed. Campinas: Papirus; 1998

(7) Kübler-Ross E. Sobre a morte e o morrer. Trad. de Paulo Menezes, São Paulo: Martins Fontes; 1989.

(8) Martins JS. A morte e os mortos na sociedade brasileira. São Paulo: Hucitec; 1983.

(9) Ziegler J. Os vivos e a morte. Trad. de Áurea Weissenberg. Rio de Janeiro: Zahar; 1977.
(10) Popim RC, Barbieri A. O significado da morte perinatal - depoimentos de mães. Rev Gaúcha Enferm 1990; 11(1):33-40.

(11) Longo RT. Estudo sobre aborto - uma primeira aproximação. [Trabalho apresentado no $48^{\circ}$ Congresso Brasileiro de Enfermagem; 1996 out 6-11; São Paulo].

(12) Oliveira EM. A ética do ponto de vista das mulheres que abortam. Universidade Sociedade 1999; 9(20):80-82.

(13) Biancarelli A. Aborto: decisão vai orientar políticas públicas de saúde para os próximos anos- Conferências em Brasília aprova descriminalização. Folha de São Paulo, 2000 $\operatorname{dez} 22$.

(14) Verardo MT. Aborto - um direito ou um crime. 5a ed. São Paulo: Moderna; 1986 (coleção polêmica).

(15) Peres A. Aborto - o futuro da lei. Rev Cláudia 1999; 4(78):60.

(16) Gollop TR. Abortamento. In: Garrafa V, organizador. A bioética no séc XXI. Brasília: Universidade de Brasília; 2000. p.79-84. 
(17) Almeida M. Considerações bioéticas sobre o aborto. In: Garrafa V, organizador. A bioética no século XXI. Brasília: Universidade de Brasília; 2000. p.101-107.

(18) Azevedo ES. Aborto. In: Garrafa V, organizador. A bioética no séc XXI. Brasília: Universidade de Brasília; 2000. p.85-100.

(19) Conselho Federal de Medicina. Aborto: um problema ético de saúde pública. Rev Bioética 1994; 2(1):37-43.

(20) Almeida MS, Brito RS, Enders BC. Conhecimentos de universitários do sexo masculino sobre o aborto provocado. Rev Bras Enferm 2000; 53(2):173-182.

(21) Martins J, et al. A fenomenologia como alternativa metodológica para pesquisa - algumas considerações. Rev Esc Enferm USP 1990; 24(1):139-147.

(22) Martins J, Bicudo MAV. A pesquisa qualitativa em psicologia: fundamentos e recursos básicos. São Paulo: Moraes; 1989.

(23) Martins J. Um enfoque fenomenológico do currículo: educação como Poíesis. São Paulo: Cortez, 1992.

(24) Beaini RC. À escuta do silêncio: um estudo sobre linguagem no pensamento de Heidegger. São Paulo: Cortez; 1981.
(25) Carvalho AS. Metodologia da entrevista: uma abordagem fenomenológica. Rio de Janeiro: Agir; 1997.

(26) Mariscal JDO. Direitos sexuais e reprodutivos das mulheres. CREMESP; 4(15):2-9.

(27) Souza VLC, et al. Árvore nova dando frutos antes do tempo: o aborto entre adolescentes. Rev Baiana Enferm 2000; 13(1/2):45-54.

(28) Pedrosa IM, Garcia TR. "Não vou esquecer nunca": A experiência feminina com o abortamento induzido. Rev Lat Am Enferm 2000; 8(6):50-58.

(29) Dresler ED, Boemer MR. O significado do cuidado do paciente com AIDS - uma perpectiva de compreensão. Rev Bras Enferm 1991; 44(1):70-81.

(30) Sampaio MA, Boemer MR. Suicídio - um ensaio em busca de um desvelamento do tema. Rev Esc Enferm USP 2000; 34(4):325-331.

(31) Rezende J. Obstetrícia. Rio de Janeiro: Guanabara Koogan; 1974

(32) Rosas CF. O aborto e o segredo médico. CREMESP 2000; 3(13):28.
A mulher em situação de abortamento: um enfoque existencial 